\title{
Apport d'une étude transcriptomique et comportementale aux connaissances de l'impact des obstacles aquatiques sur les anguillettes migrantes
}

\section{Contribution of transcriptomic and behavioral studies to the knowledge on impact of water obstacles on migratory young eels}

\author{
T. Podgorniak ${ }^{1}$, E. De Oliveira ${ }^{2}$, F. Daverat ${ }^{1}$, F. Pierron ${ }^{3,4}$ \\ 1 Irstea Bordeaux, UR EABX, HYNES, 50 avenue de Verdun, 33612 Cestas cedex, France \\ tomasz_podgorniak@hotmail.fr \\ 2 EDF R\&D LNHE, HYNES, 6, quai Watier, Bat Q, 78400 Chatou, France \\ 3 Univ. Bordeaux, EPOC, UMR 5805, 33400 Talence, France \\ ${ }^{4}$ CNRS, EPOC, UMR 5805, 33400 Talence, France
}

Résumé - L'anguille européenne Anguilla anguilla est une espèce catadrome avec un cycle de vie complexe incluant des migrations entre la mer de Sargasses, l'Europe et l'Afrique du Nord. Du fait de sa baisse drastique de population depuis 30 ans, l'anguille est considérée aujourd'hui comme «en danger critique d'extinction». Une des causes de ce déclin est la fragmentation de l'habitat. L'hypothèse de pression de sélection des obstacles aquatiques exercée sur les jeunes anguilles en migration a été étudiée avec une approche sans a priori, où un grand nombre de gènes a été analysé dans trois tissus (cerveau, foie, muscle) de chaque poisson provenant des zones amont/aval de l'obstacle. Les différences de transcription des gènes au niveau du cerveau des poissons ont été détectées. Ces différences sont liées à la plasticité neuronale et se maintiennent sur le long terme. De plus, il a été montré que les anguilles provenant des zones amont possèdent la tendance à l'escalade la plus forte et que certains poissons classés comme «leaders " d'escalade présentaient des niveaux de transcription de gènes liés à la cognition plus faibles que les "suiveurs". Ces résultats peuvent être associés au concept de coping style et de la personnalité animale. En effet, les «leaders » agiraient comme des individus proactifs et téméraires, contrairement aux suiveurs, plutôt réactifs et timides. L'implication de notre étude est discutée dans le contexte écologique, car la présence des obstacles peut modifier les patterns de distribution de phénotypes dans les réseaux aquatiques.

Mots-clés - anguille, cerveau, transcription, comportement, barrages

\footnotetext{
Abstract - The European eel Anguilla anguilla is a catadromous fish with a large scale migration loop including the Sargasso sea, Europe and North Africa. In the last 30 years, drastic declines of abundance have been observed and the species is currently considered
} 
as critically endangered. One of the causes of species decline is habitat fragmentation, which prevents migrating fish from accessing growth zones. We studied whether aquatic obstacles can enact selectively on migrating young eels by applying a no a priori approach to detect any traits involved in the process of obstacle passage. We used a microarray analysis for gene expression screening in three tissues (brain, liver, muscle) of young eels sampled in different sections of an impounded watercourse. The only differences detected between groups of fish concerned the brain tissue, were related to synaptic plasticity, and were stable in time. Moreover, upstream fish had the highest climbing tendency and that the 'climbing' leaders showed lower transcription levels of cognition-related gene than the fish following them. The leaders could enact as bold and proactive individuals, in contrast to reactive followers. The implication of our results is discussed in an ecological context, where the presence of water obstacles can modify the distribution of different phenotypes in the upstream and downstream parts of the water axis.

Key words - eel, brain, transcription, behaviour, dams

\section{Introduction}

\subsection{Problématique et contexte}

Les divers ouvrages installés sur l'axe fluvial rendent bien des services à l'homme, mais peuvent empêcher la libre circulation de tous les organismes aquatiques. La manière dont ces derniers répondent à la fragmentation dépend de leurs capacités naturelles de dispersion (Pépino et al., 2012). En effet, les espèces à fort potentiel dispersif ou les espèces migratrices diadromes sont parmi les plus touchées (McDowall, 1988). En effet, de nombreux bassins sont rendus inaccessibles aux poissons migrateurs suite à la construction d'obstacles sur leurs axes migratoires (Nicola et al., 1996; Larinier, 2001). En France, l'installation de seuils et barrages sur les cours d'eau ou sur les estuaires s'est pratiquement toujours traduite par la raréfaction, voire la disparition des espèces migratrices en amont de ceuxci. La présence d'obstacles est donc considérée comme l'une des causes essentielles de la diminution de l'aire de répartition de l'anguille et du saumon (Larinier, 2001). Ces ouvrages exercent en effet des pressions multiples sur la faune piscicole, non seulement en limitant ou interdisant la libre circulation amont-aval, mais aussi en modifiant les propriétés physico-chimiques de l'habitat des poissons (Croze \& Larinier, 2007). L'écosystème de la rivière est constitué de microhabitats hétérogènes, permettant la création de niches écologiques diverses, maintenant ainsi un potentiel d'accueil important vis-à-vis de la biodiversité aquatiques. La fragmentation des axes aquatiques par des ouvrages de grande taille comme les barrages des centrales hydroélectriques peut aboutir à la création de deux habitats amont/ aval aux conditions «extrêmes » à l'échelle inter-habitat, mais aux conditions homogènes à l'échelle intrahabitat, pas nécessairement propices à une forte biodiversité locale. 
Les obstacles aquatiques limitent l'accès aux zones amont des bassins versants qui sont essentielles à l'accomplissement du cycle de vie des espèces diadromes. L'habitat amont constitue le site de fraie pour le saumon, alors qu'une partie des juvéniles d'anguille s'y rendent pour y effectuer leur phase de croissance somatique.

Cette connectivité restreinte entre les habitats de croissance et de reproduction impactent aussi indirectement les espèces diadromes en provoquant des retards de migration et une accumulation des individus au pied des obstacles. Ces retards de migration peuvent être liés au temps nécessaire pour franchir l'obstacle, ou, dans le cas des obstacles équipés des dispositifs de franchissement, à la difficulté de trouver l'entrée du dispositif, au mauvais positionnement de la passe ou encore à la faible attractivité de celle-ci. Dans tous les cas, quel que soit le type d'obstacle ou sa franchissabilité, son passage peut entraîner un certain retard dans la migration des individus par rapport au temps du passage dans un axe libre d'obstacles. Dans certains cas, ce décalage temporel peut être crucial pour l'individu, car il risque d'atteindre la zone de frayère en dehors de la fenêtre de reproduction optimale et limiter ainsi son succès reproducteur. Ce délai peut également entraîner une diminution trop importante des réserves énergétiques stockées et non renouvelables, et ainsi compromettre l'accès des individus aux zones de fraie (Hasler et al., 2009). Les seuils et barrages peuvent également avoir un impact néfaste sur les individus en montaison en concentrant les poissons à leur pied, ce qui exacerbe leur vulnérabilité aux prédateurs, à la maladie et/ou mortalités densité-dépendantes.

La prise de conscience de l'impact des barrages sur la connectivité écologique a poussé les gestionnaires à construire des dispositifs de franchissement. En France, les premiers efforts en vue de faciliter le passage des poissons ont été mentionnés au $17^{\mathrm{e}}$ siècle, où des tas de branches d'arbres ont été placés sur les zones à fort dénivelé, afin de "casser» le courant et créer des zones de repos dans les endroits où le poisson est exposé à la forte courantométrie. Aujourd'hui, il existe une gamme très large de dispositifs de franchissement répartis sur toute la France (Travade, 2005) (Fig. 1), dont le design répond aux caractéristiques de l'environnement, au type d'obstacle aménagé, mais aussi à la biologie et aux capacités de nage de l'espèce visée.

L'anguille européenne Anguilla anguilla est une espèce catadrome facultative, effectuant deux migrations transocéaniques, ces déplacements étant liés d'abord à la recherche d'un milieu propice à la croissance (colonisation des milieux d'eau douce ou saumâtres continentale), puis ensuite à la reproduction dans la Mer de Sargasses, lieu unique de fraie. Le choix de cette espèce pour notre étude se justifie par le déclin drastique de la population d'anguille et la prise de conscience de l'impact de la fragmentation des corridors aquatiques sur cette espèce de poisson migrateur.

Dans le cas de l'anguille, l'impact de la fragmentation peut avoir lieu à deux stades différents (juvénile et adulte). 


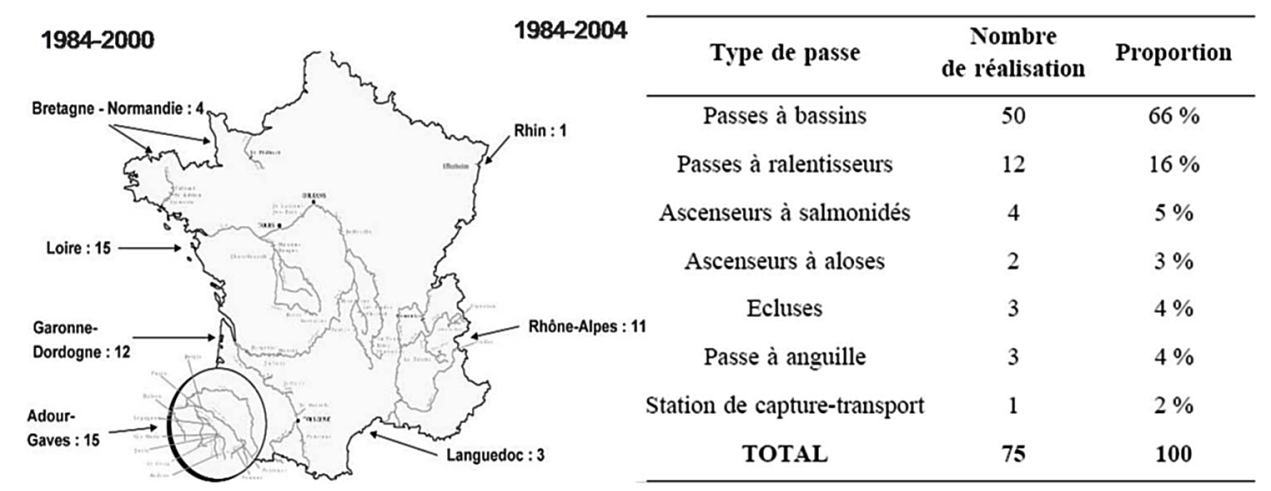

Fig. 1. Répartition géographique des passes et nombre par type des passes construites sur les barrages EDF de 1984 à 2000 (carte, gauche) et de 1984 à 2004 (tableau, droite) en France (Travade, 2005).

Fig. 1. Geographical repartition of fishways and the number of fishways built on EDF water dams from 1984 to 2000 (map, left) and from 1984 to 2004 (table, right) in France (Travade, 2005).

Lors de la première migration, les civelles et anguillettes ne peuvent pas accéder aux zones de croissance situées en amont. Les individus peuvent se retrouver coincés au pied des obstacles, ce qui aurait d'autres impacts indirects; la transmission des maladies serait facilitée, et le sex-ratio, souvent considéré comme dépendant de la densité, serait modulé en faveur des mâles (Davey \& Jellyman, 2005). Ensuite, si la phase de croissance a été effectuée en amont des obstacles, la migration de reproduction nécessite à nouveau un passage par les barrages. Cette fois, une mortalité accrue peut être observée chez les individus de grande taille qui, dans le cas des centrales hydroélectriques, sont attirés dans les zones où le fort débit d'eau passe par les hélices des turbines génératrices d'énergie. De nombreuses études et simulations portent sur le taux de mortalité des anguilles en fonction de la taille de leur corps et du type de turbine utilisé (Gomes \& Larinier, 2008; Larinier \&
Dartiguelongue, 1989). De plus, l'impact cumulé de la fragmentation des voies migratrices peut avoir lieu dans le cas de plusieurs obstacles successifs (Ward \& Stanford, 1979).

Des dispositifs visant à améliorer le franchissement des barrages par les anguilles prennent également en compte le stade de l'espèce concernée. Si pour le stade adulte, on pourrait adapter certains types de passes multiespèces (en réduisant, par exemple, la hauteur de chute entre les bassins ou ajoutant de la rugosité de fond), pour les jeunes stades d'anguille (civelle et anguillette) on favorisera un aménagement spécifique basé sur les capacités d'escalade des individus. En effet, les passes spécifiques aux anguilles de petite taille sont souvent appelées "échelles à anguilles" (eel ladder). L'installation d'une passe de ce type fait souvent l'objet d'études préalables visant à localiser le meilleur emplacement sur l'obstacle, tout en estimant l'efficacité de la passe. Cependant, l'analyse quantitative (Cote et al., 
2009) de l'efficacité des passes à poissons ne peut pas donner d'indications sur leur sélectivité. Autrement dit, le passage facilité par les passes peut sélectionner des individus présentant des caractéristiques particulières (bonne capacité de reptation, réserves énergétiques importantes, comportement explorateur), créant par la même des groupes de poissons en amont et en aval avec des traits différents.

\subsection{Objectifs de l'étude}

La présente étude concerne une analyse qualitative des passes à anguillettes. Elle synthétise des travaux menés dans la thèse de Podgorniak (2016). Cette étude a pour but de détecter les différences de traits entre les groupes d'anguillettes en amont et en aval des obstacles aquatiques. Elle est composée de trois parties:

- étude préliminaire des niveaux de transcription d'un large nombre de séquences génétiques au moyen d'une puce à ADN;

- vérification de la persistance des différences de transcription des gènes au moyen d'une expérience de Common Garden (i.e. le maintien prolongé des poissons sous des conditions homogènes);

- association du comportement d'escalade et des niveaux de transcription de gènes au moyen du test de la Passe Expérimentale.

Chaque étude est réalisée sur trois cohortes successives d'anguillettes, prélevées annuellement sur le même axe aquatique. La première partie de l'étude s'est inscrite dans une appro- che d'analyse sans a priori des traits suggérés comme fortement impliqués dans la migration des civelles et anguillettes dans la littérature scientifique et a permis de tester l'hypothèse des profils d'expression génétique différents entre les groupes des poissons en amont et en aval de l'obstacle. La deuxième partie de l'étude (l'expérience de Common Garden) a permis de tester l'hypothèse de la persistance des profils transcriptomiques entre les différents groupes des poissons indépendamment des conditions environnementales. Elle a également permis de donner un aperçu sur les mécanismes impliqués dans la régulation de l'expression des gènes et par conséquent le phénotype (i.e. les caractéristiques observables) de l'individu. En effet, la stabilité temporelle des différences de transcription peut indiquer si l'expression du phénotype est la résultante de la plasticité phénotypique (i.e. la modification des traits phénotypiques causée par les conditions environnementales). La troisième partie de l'étude (le test de la Passe Expérimentale) a permis de tester l'hypothèse des liens directs entre le comportement d'escalade des obstacles, c'est-à-dire le comportent crucial pour l'accès aux zones amont des axes fragmentés, et les niveaux d'expression des gènes sélectionnés sur la base des résultats des études précédentes.

\section{Méthodes}

\subsection{Site d'échantillonnage}

L'échantillonnage a eu lieu au Canal du Porge, un axe reliant le lac Lacanau au Bassin d'Arcachon. Cette section 


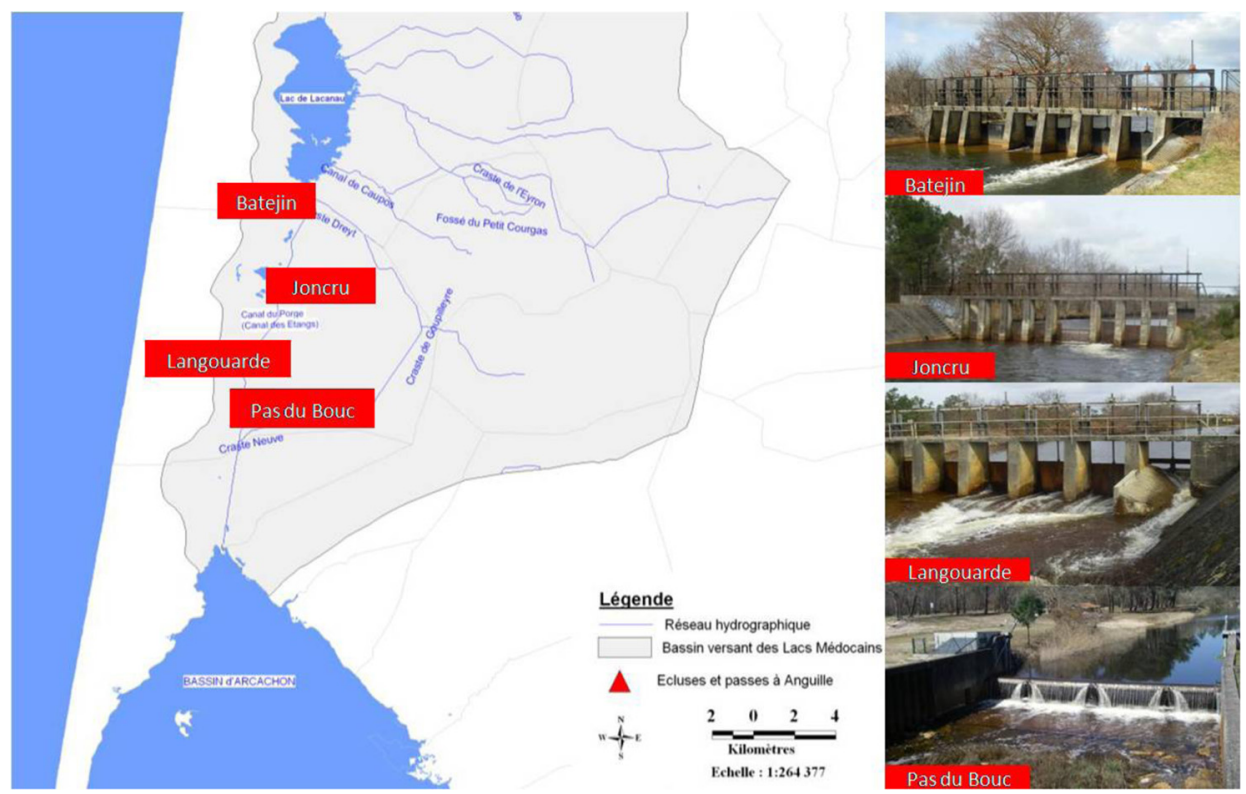

Fig. 2. Sites d'échantillonnage sur le Canal du Porge (Photos: @FDAAPPMA 33).

Fig. 2. Sampling sites on Canal du Porge (Photos: $\odot F D A A P P M A 33)$.

fait partie d'un autre axe plus large, le Canal des Etangs, qui se jette dans le Bassin d'Arcachon au niveau de LègeCap-Ferret (près de $6 \mathrm{~km}$ en aval), à environ $15 \mathrm{~km}$ de l'océan. Le Canal du Porge mesure $18,5 \mathrm{~km}$ et, avec les $7,5 \mathrm{~km}$ du Canal des étangs, il représente un réseau de $500 \mathrm{~km}$ de fossés et tributaires des lacs. Le Canal du Porge est un axe d'origine anthropique, d'une vitesse de courant moyenne de $0,5 \mathrm{~m} / \mathrm{s}$ (réduite en période estivale), d'une largeur de 35 mètres et présentant des conditions abiotiques relativement stables sur toute sa longueur. II est peuplé par une dizaine d'espèces piscicoles et deux espèces de crustacés, cette communauté étant représentée principalement par l'anguille Européenne, la perche soleil, l'écrevisse de Louisiane et l'écrevisse signal.
L'axe du Canal du Porge est divisé par 4 écluses successives (Fig. 2), construites à la fin $\mathrm{du} \mathrm{XIX}^{\mathrm{e}}$ siècle.

L'écluse du Pas du Bouc (hauteur= 1 mètre) constitue la première entrave à la migration en amont des civelles. Elle est située à environ $6 \mathrm{~km}$ de la limite du Bassin d'Arcachon. Cet obstacle a été équipé en 2007 d'un dispositif de passage pour les civelles. La passe à civelles a été implantée sur la rive droite du Canal, sous un abri sécurisé, et est constitué d'une rampe de $4,30 \mathrm{~m}$ de long, inclinée à $45^{\circ}$. Le substrat de la rampe de reptation est un tapis artificiel Fishpass ${ }^{\circledR}$ constitué de faisceaux de soies en plastique. La rampe est alimentée par une goulotte distribuant de l'eau sur la rampe et dans le bac de stabulation/ piégeage. 


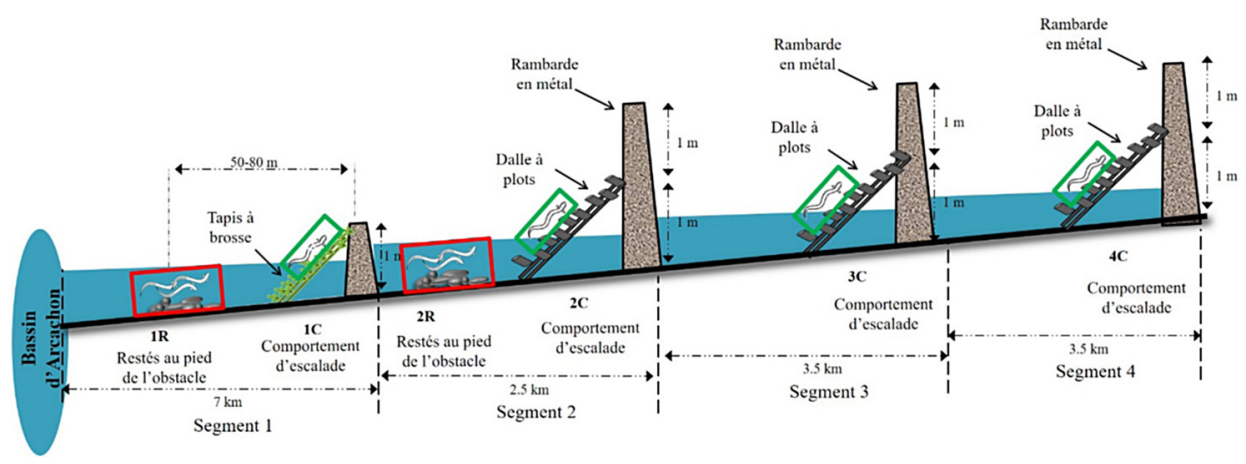

Fig. 3. Schéma des sites d'échantillonnage. Les groupes d'individus échantillonnés sur la passe sont appelés « $C$ », et ceux échantillonnés au pied de l'obstacle sont appelés « $R$ ». Cette appellation du groupe est précédée du chiffre correspondant au numéro du segment dans l'axe aval-amont.

Fig. 3. Scheme of the sampling sites. Fish sampled directly on the fishways were called "C", whereas those sampled below the obstacle were called " $R$ ". This denomination is preceded by the number designing the number of the segment on the downstream-upstream axis.

Les écluses de la Langouarde, du Joncru et du Batejin, situées respectivement à $2,5 / 6$ et $8,5 \mathrm{~km}$ à l'amont de l'écluse du Pas du Bouc possèdent une structure similaire; le corpus de l'obstacle étant une dalle métallique verticale de 2 mètres de hauteur (Fig. 3). Seule la profondeur en aval de l'obstacle peut différer entre les écluses. Sur le site de la Langouarde, tout comme sur le site du Pas du Bouc, la profondeur au pied de l'obstacle reste faible $(<1 \mathrm{~m})$ et permet l'usage du matériel de pêche électrique. Sur les sites de Joncru et Batejin, la profondeur au pied de l'obstacle est d'environ 3 mètres et la prospection par pêche électrique n'est pas possible. Les trois obstacles sont équipés du même type de dispositif de passage, sous forme d'une dalle en béton recouverte par des plots cylindriques.

Tous les prélèvements effectués durant cette étude ont porté sur cet axe ; l'échantillonnage a été réalisé à la fin de la période de migration estivale (début juin -fin juillet) sur trois années consécutives. L'échantillonnage vers la fin de la période de migration a permis de se rapprocher de la distribution réelle des individus migrants et des individus sédentaires, bien que la probabilité de capturer quelques individus «migrants tardifs» seulement dans les zones aval ne soit pas nulle. La capture a été réalisée par pêche électrique ou par récupération directe des individus escaladant ou piégés (au niveau de la passe du Pas du Bouc).

Pour chacun des quatre obstacles il était possible d'échantillonner des individus en train d'escalader la passe lors d'une ou plusieurs études. De plus, pour les deux premiers sites, la profondeur d'eau en aval a permis un échantillonnage des individus au pied de l'obstacle. Compte tenu de contraintes liées au statut protégé de l'anguille et du nombre limité d'échantillons autorisées au prélèvement, il n'était pas possible d'échantillonner l'ensemble des sites durant la même saison de migration. Bien que l'appellation des groupes échantillonnés 
puisse différer entre les articles publiés, on associera à un groupe par une lettre « $\mathrm{C}$ » (=Climbing) ou « $\mathrm{R}$ » (= Remaining, Resting) et par un chiffre correspondant au numéro du segment dans l'axe aval-amont (1, 2, 3, 4) (Fig. 3).

Pour chaque étude, un échantillon d'anguillettes de 8 à $12 \mathrm{~cm}$ a été prélevé sur différents sites et les mesures de la taille et du poids des poissons ont été enregistrées. Ensuite, tous les individus ont été soit immédiatement sacrifiés (analyse préliminaire), soit transportés vivants jusqu'à la Station d'Expérimentation de Saint Seurin (Irstea Bordeaux) pour les tests expérimentaux (Common Garden/Passe Expérimentale). La méthode d'euthanasie était le sacrifice par décapitation (coupure nette au niveau de la medulla oblongata).

Les prélèvements du tissu musculaire, cervical et hépatique (étude préliminaire) ou du tissu cervical seul (expérience de Common Garden/Passe Expérimentale) ont été réalisés et les échantillons mis dans l'azote liquide pour être ensuite conservés dans les cryotubes à $-80^{\circ} \mathrm{C}$, pour une analyse transcriptomique ultérieure. L'extraction des otolithes (concrétion minérale de l'oreille interne du poisson) fut également réalisée, et l'otolithomètrie (i.e. estimation d'âge) a permis de confirmer que les individus étudiés se trouvaient dans leur première année post-métamorphose au moment d'échantillonnage.

\subsection{Analyses transcriptomiques}

Lors de l'étude préliminaire, l'analyse des niveaux de transcription a été faite au moyen de puce à ADN, permettant une comparaison simulta- née d'environ 15000 séquences génétiques provenant des trois tissus (cerveau, muscle, foie) des poissons des différents sites d'échantillonnage. Le protocole détaillé de cette analyse a été précédemment décrit (Podgorniak et al., 2015a). En ce qui concerne les analyses des individus utilisés pour les expériences de Common Garden et de Passe Expérimentale, le niveau de transcription des gènes sélectionnés après l'étude préliminaire a été faite au moyen de la RT-qPCR. La description de cette méthode a été décrite par ailleurs (Podgorniaketal., 2015b, 2016). La sélection des gènes dans l'expérience de Common Garden (Fig. 6) et dans l'expérience de la Passe Expérimentale (Fig. 8) avait pour but de vérifier les différences de niveaux de transcription détectées préalablement (Tab. II) et de tester les nouveaux gènes associés à la fonction biologique de gènes détectée lors de l'étude préliminaire (Fig. 5).

\subsection{Tests expérimentaux}

Deux tests expérimentaux ont été menés dans le Station d'Expérimentation IRSTEA de Saint Seurin suite à l'étude préliminaire (Tab. I).

L'expérience de Common Garden consistait à maintenir les individus de la même provenance que les individus utilisés pour l'étude préliminaire sous des conditions strictement homogènes pendant deux mois, dans le but de vérifier si les différences entre les groupes étaient liées aux conditions environnementales du site d'échantillonnage. À la fin de l'expérience, les niveaux de transcription des gènes d'intérêt ont été comparés entre les 
Tableau I. Trois parties successives de l'étude.

Table 1. Three successive parts of the study.

\begin{tabular}{ccccccc}
\hline Expérience & Objectif & Année & $\begin{array}{c}\text { Site } \\
(\text { nombre })\end{array}$ & $\begin{array}{c}\text { Taille } \\
(\mathrm{mm})\end{array}$ & $\begin{array}{c}\text { Tissu } \\
\text { analysé }\end{array}$ & $\begin{array}{c}\text { Methode } \\
\text { d'analyse }\end{array}$ \\
\hline Analyse & Detection & 2012 & $1 \mathrm{R}(10)$ & $90-120$ & $\begin{array}{c}\text { Cerveau } \\
\text { foie }+\end{array}$ & Puce ADN \\
préliminaire & $\begin{array}{c}\text { des genes } \\
\text { différament }\end{array}$ & & $3 \mathrm{R}(10)$ & & & \\
& transcrits & & & & & \\
muscle & & \\
Gommon & Vérifier la & 2013 & $1 \mathrm{R}(21)$ & $90-110$ & Cerveau & qRt-PCR \\
& persistence & & $2 \mathrm{R}(26)$ & & & \\
des profils & & $3 \mathrm{C}(29)$ & & & \\
Passe & transcriptomiques & & & & & \\
Expérimentale & Associer le & 2014 & $1 \mathrm{R}(11)$ & $80-90$ & Cerveau & qRT-PCR + \\
& comportement & & $1 \mathrm{C}(9)$ & & & comportement \\
& aux profils & & $3 \mathrm{C}(15)$ & & & \\
\hline & transcritpomiques & & $4 \mathrm{C}(14)$ & & & \\
\hline
\end{tabular}

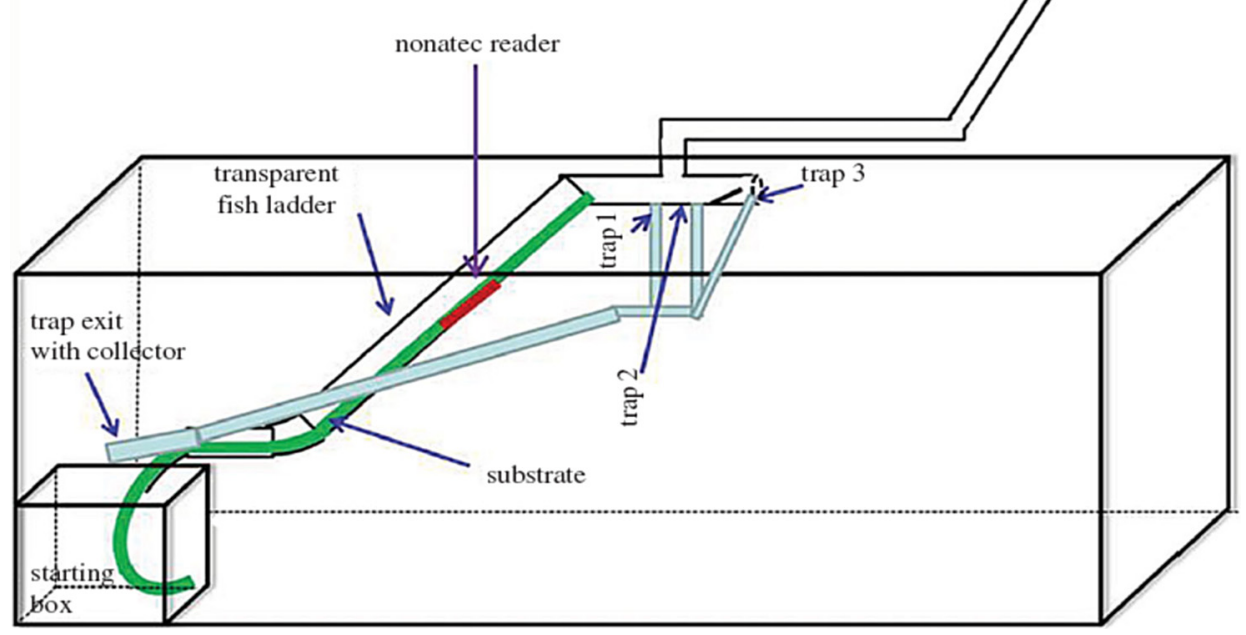

Fig. 4. Schéma du dispositif de la Passe Expérimentale.

Fig. 4. Scheme of the Experimental Fishway device.

individus des différentes provenances. $\mathrm{Si}$ les différences persistent, alors elles peuvent être attribuées à la composante génétique/épigénétique des individus et non aux conditions environnementales différentes. L'expé- rience de la Passe Expérimentale consistait à soumettre les individus à un dispositif simulant la passe à anguillettes de type "échelle " (Fig. 4). Les individus des différentes provenances pouvaient librement 
escalader le dispositif lors d'une série de 4 tests de 5 heures, et leur temps d'escalade, l'ordre d'escalade ainsi que le nombre d'escalades totales et per test ont été enregistrés individuellement, ce qui a permis de les classer dans différents groupes de «peloton » (les «leaders» étant les premiers à escalader, suivis par les «followers», puis les « finishers », les « no climbers » étant ceux qui n'ont jamais escaladé la passe) et d'estimer la répétabilité de leur comportement (la cohérence entre les ordres de passage et nombre de passages par test). Afin de permettre une analyse individuelle lors de l'expérience de Common Garden et de la Passe Expérimentale, chaque individu a été préalablement marqué à l'aide d'un tag RFID (NONATEC, Lutronic, taille $6 \mathrm{~mm} \times 1 \mathrm{~mm}$ ).

\section{Résultats et interprétation}

\section{1 Étude préliminaire}

L'analyse du niveau de transcription de 15000 séquences génétiques réalisée sur trois tissus différents a montré que le foie ne présentaient aucune différence significative entre les groupes d'individus provenant des différents segments échantillonnés le long de l'axe du Canal du Porge (analyse $\mathrm{SAM}, \mathrm{FC}>1,5$, seuil $\mathrm{FDR}=5 \%$, aucun gène détecté). En ce qui concerne le muscle, bien que ce tissu provenant des individus du $3^{\mathrm{e}}$ segment n'était pas disponible, l'absence de différences dans le muscle entre les poissons des deux premiers segments (analyse $\mathrm{SAM}, \mathrm{FC}>1,5$, seuil $\mathrm{FDR}=5 \%$, aucun gène détecté) a suggéré que ni la distance de nage entre les sites ni le type de passe escaladée n'influençaient l'expression de gènes impliqués entre autres dans les métabolismes aérobies ou anaérobies. Or, ces derniers pourraient nous renseigner sur les capacités de nage des poissons (Garenc et al., 1998; Martinez et al., 2003).

En revanche, des différences significatives ont été détectées dans le cerveau, en particulier entre les individus échantillonnés à Joncru et ceux à Pas du Bouc. Un lot de 40 séquences génétiques correspondant à 26 gènes uniques a été identifié (Tab. II). Tous ces gènes étaient surexprimés dans le cerveau du groupe d'individus capturés en amont. La fonction commune à la majorité de ces gènes concernait la plasticité synaptique et la neurogenèse (Fig. 5). Ces fonctions peuvent être associées aux processus cognitifs tels que l'acquisition de la mémoire spatiale, la perception des nouveaux stimuli ou la prise de décisions.

Ces résultats ont permis de définir les expériences qui ont suivi l'étude préliminaire:

Peu de différences ont été observées entre les individus échantillonnés au pied du premier et deuxième obstacle, généralement cachés dans la végétation ou sous les galets. Les différences les plus fortes concernent l'ensemble de deux groupes échantillonnés au pied d'obstacles (premier et deuxième obstacle) comparés au groupe échantillonné lors du moment d'escalade de la passe (au niveau du troisième obstacle). Le test de la Passe Expérimentale réalisé par la suite a permis d'associer les niveaux de transcription des gènes avec le comportement d'escalade individuel. 
Tableau II. Liste des gènes présentant des niveaux de transcription différents entre les sites. Le facteur de multiplication (fold change, FC) indique le ratio des niveaux de transcription entre les groupes.

Table 2. List of genes with different levels of transcription among sites. The fold change (FC) indicates the ratio of transcription levels between groups.

\begin{tabular}{|c|c|c|c|c|c|}
\hline Name & Function & $\begin{array}{l}\text { EelBase } \\
\text { number }\end{array}$ & $\begin{array}{c}\text { FC 3C: } \\
1 \mathrm{R}\end{array}$ & $\begin{array}{c}\text { FC 3C: } \\
2 R\end{array}$ & $\begin{array}{l}\text { FC 3C: } 1 R \\
\text { FC 3C: } 2 R\end{array}$ \\
\hline S100P & Calcium binding & eeel2 rep c5535 & 12.7 & 6.1 & 2.1 \\
\hline S100P & Calcium binding & eeel2_s9035 & 12.4 & 6.0 & 2.1 \\
\hline S100P & Calcium binding & eeel2_s8956 & 11.8 & 6.7 & 1.8 \\
\hline S100P & Calcium binding & eeel2_s8475 & 9.8 & 6.1 & 1.6 \\
\hline S100A11 & Calcium binding & eeel_rep_c16089 & 16.1 & 7.4 & 2.2 \\
\hline S100A11 & Calcium binding & eeel_rep_c58988 & 15.1 & 7.4 & 2.0 \\
\hline S100A11 & Calcium binding & eeel2_rep_c5969 & 14.0 & 7.3 & 1.9 \\
\hline S100A6 & Calcium binding & eeel2_s6035 & 14.3 & 6.5 & 2.2 \\
\hline S100A1 & Calcium binding & eeel2_rep_c8719 & 14.2 & 7.1 & 2.0 \\
\hline S100A1 & Calcium binding & eeel2_s9222 & 12.0 & 9.1 & 1.3 \\
\hline Keratin 5 & Cell structure & eeel_rep_c59287 & 29.2 & 14.5 & 2.0 \\
\hline Keratin 12 & Cell structure & eeel2_rep_c5249 & 5.2 & 4.4 & 1.2 \\
\hline Keratin 12 & Cell structure & eeel2_s8804 & 7.8 & 8.3 & 0.9 \\
\hline Keratin 12 & Cell structure & eeel_c8960 & 8.0 & 8.5 & 0.9 \\
\hline Cytokeratin 1 & Cell structure & eeel_rep_c58375 & 6.9 & 7.2 & 1.0 \\
\hline Cytokeratin 1 & Cell structure & eeel_c10204 & 7.3 & 7.7 & 0.9 \\
\hline Keratin & Cell structure & eeel_c5504 & 7.7 & 8.7 & 0.9 \\
\hline Keratin & Cell structure & eeel_c13622 & 8.3 & 9.0 & 0.9 \\
\hline Non muscle cofilin 1 & Neural growth & eeel2_s5802 & 4.8 & 3.3 & 1.4 \\
\hline Non muscle cofilin 1 & Neural growth & eeel2_s5819 & 4.0 & 3.0 & 1.3 \\
\hline Non muscle cofilin 1 & Neural growth & eeel2_s5889 & 3.6 & 3.0 & 1.2 \\
\hline C59 protein & Bacterial infection & eeel_c3624 & 9.2 & 3.0 & 3.1 \\
\hline Thy 1 protein & Surface glycoprotein & eeel_c9925 & 9.4 & 3.9 & 2.4 \\
\hline SH3 protein & Unknown in brain & eeel2_rep_c5904 & 10.9 & 5.0 & 2.2 \\
\hline FABP protein & Neural growth & eeel2_s8168 & 10.3 & 5.0 & 2.1 \\
\hline Mucin 2 & Unknown in brain & eeel2_c3054 & 13.5 & 8.4 & 1.6 \\
\hline Intelectin 1 & Defence system & eeel2_c833 & 6.9 & 4.4 & 1.6 \\
\hline ATPase, $\mathrm{Ca}++$ transporting & Unknown in brain & eeel2_rep_c8320 & 12.3 & 7.8 & 1.6 \\
\hline Calmodulin & Synaptic signaling & eeel $c 13874$ & 11.5 & 7.4 & 1.6 \\
\hline Claudin 4 & Tight junction & eeel2_c529 & 6.1 & 4.6 & 1.3 \\
\hline Unnamed & Unknown in brain & eeel2_c497 & 4.6 & 3.7 & 1.2 \\
\hline LOC100135339 & Unknown in brain & eeel2_rep_c4986 & 12.6 & 10.3 & 1.2 \\
\hline $\mathrm{C} 2 \mathrm{~A}$ protein & Unknown in brain & eeel_rep_c35338 & 2.3 & 2.0 & 1.2 \\
\hline Zona pellucida-like protein & Unknown in brain & eeel2_s8124 & 4.6 & 4.0 & 1.2 \\
\hline C13 antigen & Unknown in brain & eeel_c14624 & 10.2 & 8.9 & 1.2 \\
\hline Proteoglycan 4 & Unknown in brain & eeel2_c3589 & 2.5 & 2.3 & 1.1 \\
\hline Serotriflin & Unknown in brain & eeel2_rep_c5326 & 3.3 & 3.2 & 1.1 \\
\hline BRAFLDRAFT_63199 & Unknown in brain & eeel2_s7960 & 2.4 & 2.5 & 1.0 \\
\hline Epiplakin & Unknown in brain & eeel_rep_c28794 & 4.1 & 5.9 & 0.7 \\
\hline Mucin5 & Unknown in brain & eeel2_c2120 & 5.3 & 9.3 & 0.6 \\
\hline
\end{tabular}

L'échantillonnage, le sacrifice et la dissection de chaque individu ont été réalisés sur place et de manière immédiate et standardisée, ainsi le niveau de transcription des gènes mesuré peut refléter les conditions auxquelles les individus étaient soumis au moment de l'échantillonnage. Cependant, les différents niveaux de transcription pouvaient être présents chez les individus bien avant qu'ils rencontrent les premiers obstacles. 




Fig. 5. Les fonctions principales des gènes dont le niveau de transcription différait entre les sites d'échantillonnage (Pas du Bouc \& Langouarde VS Joncru).

Fig. 5. Principal functions of the genes whose transcription level was different between the sampling sites (Pas du Bouc \& Langouarde VS Joncru).

La régulation de l'expression génétique peut être de courte durée ou se maintenir à long terme, de même que l'impact des obstacles peut être sélectif (le passage par obstacles accessible uniquement aux individus présentant au préalable des niveaux de transcription particuliers) ou inductif (modification de la régulation de transcription des gènes lors de passage). Par exemple, dans le cas où la sélection s'opère sur des profils moléculaires préexistants, les niveaux de transcription forts pourraient être maintenus à long terme, voire tout au long de la vie de l'animal. Dans le cas où la sélection s'opère sur la plasticité (flexibilité) phénotypique, seuls les individus aptes à solliciter l'activité des gènes à un certain niveau pourraient traverser les obstacles. Ensuite, une fois l'obstacle traversé, la transcription des gènes d'intérêt pourrait revenir à un niveau d'activité plus faible. Dans le cas de l'induction également, l'activité des gènes sollicités sur une courte période pourrait revenir à son niveau initial une fois l'obstacle passé, ou être maintenue au même niveau pour le restant de la vie de l'animal. D'une manière générale, pour déterminer si les différences dans les traits phénotypiques 

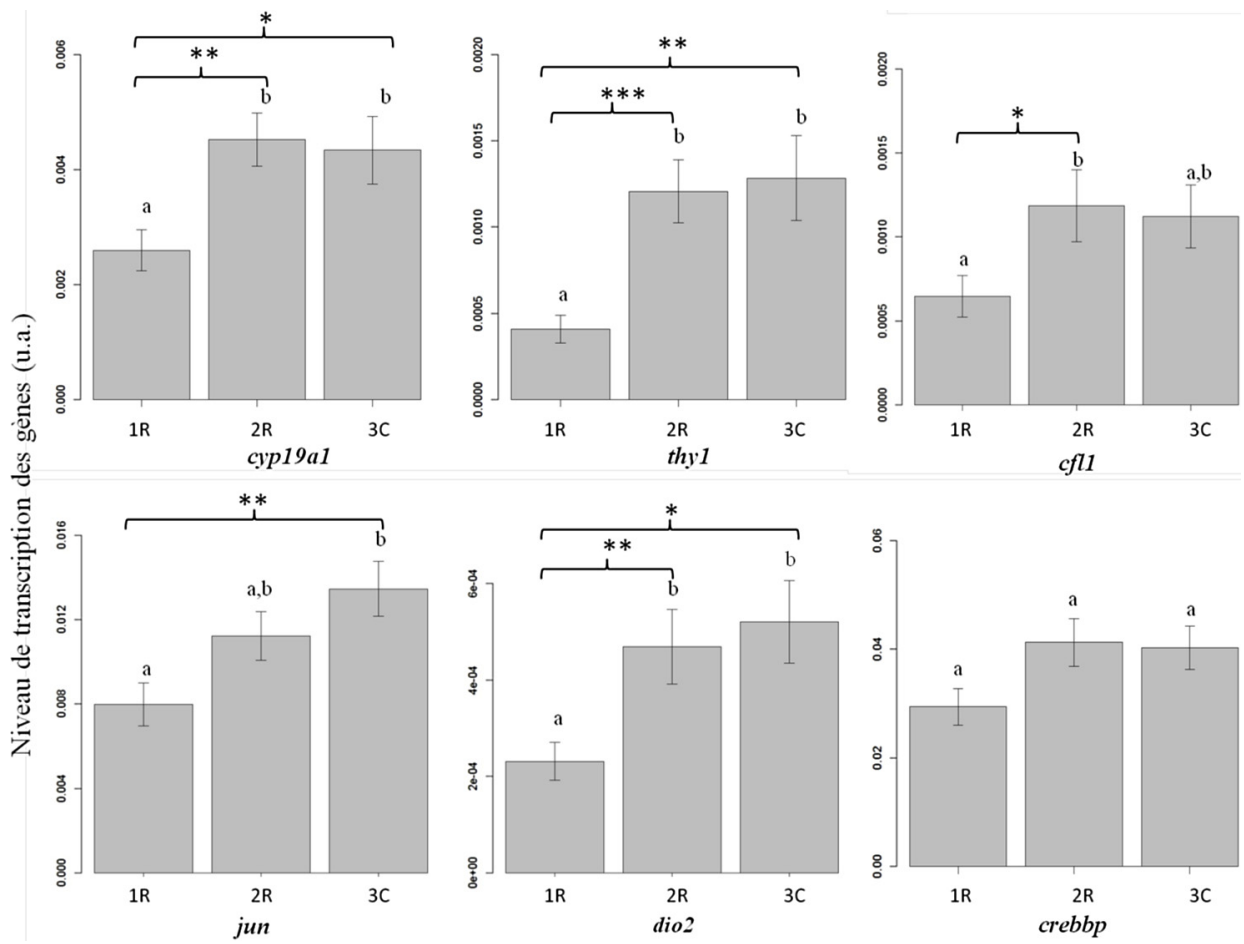

Fig. 6. Les gènes dont le niveau de transcription différait significativement entre les sites d'échantillonnage (expérience Common Garden).

Fig. 6. Genes whose transcription levels were significantly different between sampling sites (Common Garden experiment).

sont le fruit de la flexibilité phénotypique ou ont une base génétique ou épigénétique, nous avons eu recours à l'expérience de Common Garden. Lors du Common Garden, les individus exprimant des phénotypes différents ont été maintenus à long terme sous des conditions strictement homogènes. Ainsi, toute composante environnementale susceptible de jouer sur la plasticité phénotypique est la même pour tous les individus. Si les différences phénotypiques diminuent ou disparaissent à la fin de l'expérience, alors leur origine peut être associée aux conditions environnementales dans lesquels les individus se trouvaient au moment de la capture.

\subsection{L'expérience Common Garden}

Les anguillettes maintenues pendant deux mois sous des conditions strictement identiques montrent des différences dans le niveau de transcription de gènes liés, entre autres, à la plasticité synaptique et la neurogenèse. En effet, 4 gènes sur 11 testés montrent des différences significatives (Fig. 6). Ces différences sont similaires à celles observées chez les individus échantillonnés sur le terrain l'année précédente 
et analysés directement après échantillonnage, lors de l'étude préliminaire. Les individus en amont de l'axe aquatiqueayant franchi un ou plusieurs obstacles aquatiques - présentent une surexpression des gènes d'intérêt par rapport aux individus capturés en aval de l'obstacle. Les profils d'expression génétique persistent après deux mois de stabulation et concernent les gènes impliqués dans la plasticité synaptique (thy1, cfl1, jun), la neurogenèse (cyp19a1) et l'activité thyroïdienne (dio2).

Ces profils transcriptomiques différents auraient donc une base génétique ou épigénétique. S'il s'agit d'une base génétique, alors les individus présents au pied du barrage devraient présenter un pool génétique hétérogène, à partir duquel certains individus seraient sélectionnés lors du passage par le barrage. Pour vérifier cette hypothèse, une analyse de la transcription des gènes simultanément avec une analyse du polymorphisme génétique (via le séquençage et l'analyse de SNP, Single Nucleotide Polymorphism) serait adéquate (Laporte et al., 2016; Pavey et al., 2015). Il est également possible que les différences d'expression des gènes se maintiennent tout au long de la vie de l'individu sans qu'elles soient liées à des différences génétiques, mais plutôt épigénétiques.

Les résultats de l'étude préliminaire et du test de Common Garden indiquent que le cerveau joue un rôle essentiel lors du franchissement des obstacles. Or, ce tissu est responsable en quasi-totalité du comportement de l'animal. De plus, la fonction des gènes soumis à la régulation différentielle concerne entre autres la cognition, qui englobe non seulement les capa- cités de perception et d'analyse de l'environnement, mais aussi le processus de prise de décision quant au comportement à adopter. Nos résultats suggèrent fortement qu'il peut y avoir des différences dans certains traits comportementaux entre les groupes d'individus étudiés. Le comportement d'escalade mérite une attention particulière, car il doit être obligatoirement exprimé chez les individus en amont, i.e. ayant franchi avec succès l'obstacle.

Pour franchir l'obstacle, l'individu devrait d'abord exprimer la volonté d'escalader les parois (composante volontaire du comportement). Face à l'obstacle, les civelles essayent-elles toutes d'escalader les parois? Le contexte social (apprentissage social) joue-t-il un rôle lors de l'escalade des obstacles? Les individus ayant franchi un obstacle au moins une fois sont-ils plus enclins à exprimer ce comportement que les individus «naïfs» aux obstacles? Enfin, existe-t-il une relation entre la tendance des individus à escalader des obstacles et l'expression des gènes impliqués dans la cognition? Le test de la Passe Expérimentale a permis d'apporter certains éléments de la réponse à ces questions.

\subsection{Le test de la Passe Expérimentale}

Le test de la Passe Expérimentale a montré que le comportement d'escalade diffère fortement entre les individus. Le nombre moyen d'escalades par groupe diffère de manière significative entre les groupes amont/ aval, et les individus exprimant les plus fortes tendances/motivation à escalader provenaient des sites amont 


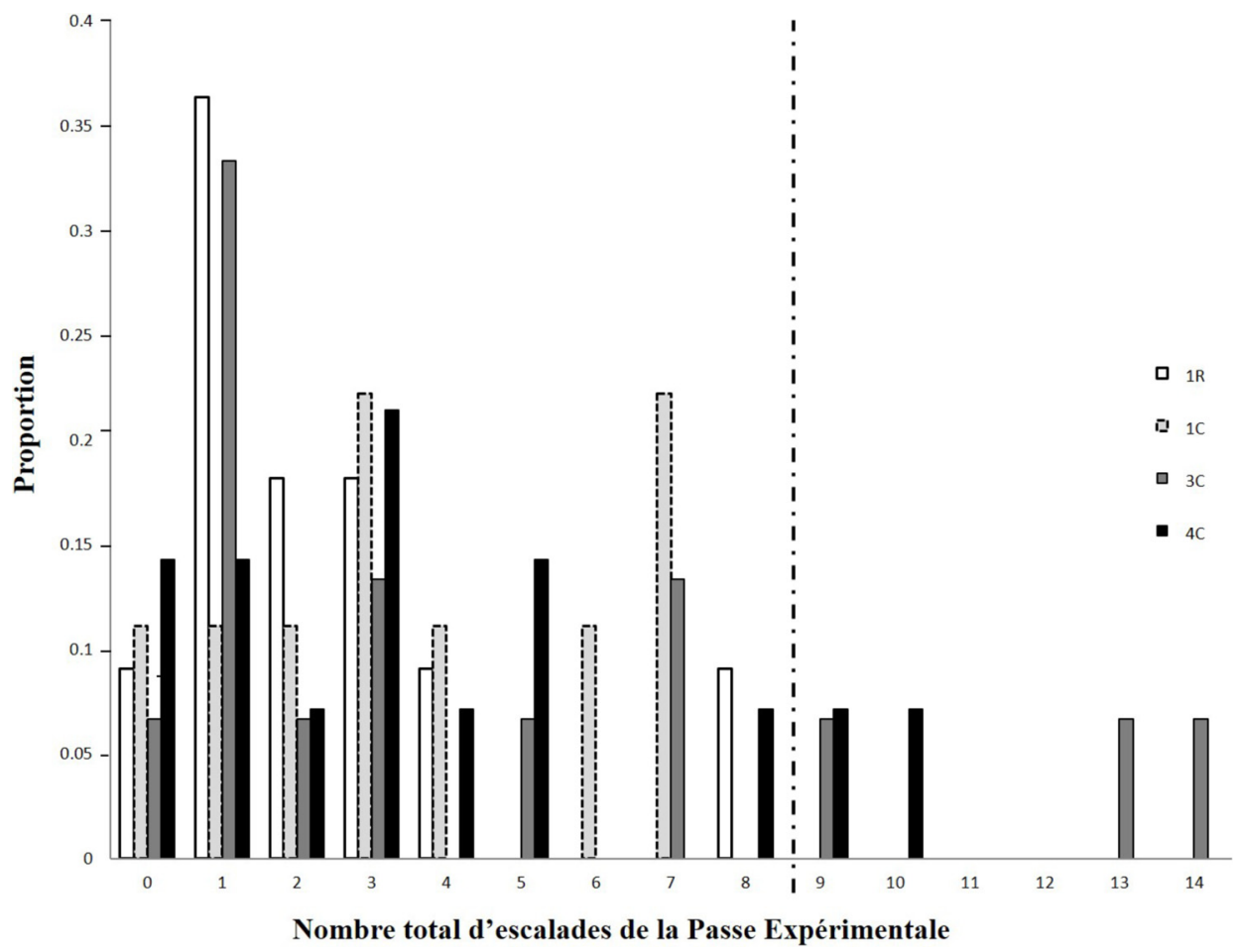

Fig. 7. Nombre total d'escalades effectué par les individus des sites d'échantillonnage différents (test de Passe Expérimentale). Les individus escaladant plus de 8 fois au total proviennent uniquement des sites amont. R: Remaining; C: Climbing; 1-4: numéro de segment de provenance du groupe.

Fig. 7. Total number of climbing events performed by individuals from different sampling sites (Experimental Fishway test). Individuals climbing more than 8 times were only from the upstream sampling sites. R: Remaining; C: Climbing; 1-4: number of the segment of origin of the group.

(Fig. 7). En effet, les individus ayant escaladé le dispositif expérimental plus de 8 fois au total provenaient uniquement des sites amont. Ce résultat peut suggérer que l'expérience acquise lors du franchissement des obstacles dans la nature peut, par le processus de renforcement, faciliter ou inciter les individus à exprimer un comportement d'escalade pendant le test de la Passe Expérimentale.

Aucune différence de niveaux de transcription de gènes n'a été détectée entre les groupes d'échantillonnage (pas de différences en fonction de l'origine), contrairement aux études précédentes. L'expression du comportement pendant le test (i.e. le nombre d'escalades et/ou l'ordre d'escalade de la Passe Expérimentale) aurait pu influencer le niveau de transcription génétique et ainsi masquer ces différences. En effet, les profils transcriptomiques ont été associés à certains comportements que les individus exprimaient lors de l'escalade. Les "leaders", i.e. individus qui sont souvent parmi les premiers à escalader 
la passe (situées dans les premiers $33 \%$ de tous les individus escaladant) au cours de chaque test (Tab. III), et exprimant le comportement de manière répétable (nombre d'escalades par test, ordre d'escalade par test) présentaient des niveaux de transcription plus faibles que le groupe d'individus qui les suivait, i.e. les "followers" (Fig. 8). Ce résultat revêt un intérêt considérable s'il est placé dans le contexte du syndrome comportemental ou du coping style de l'animal (Coppens et al., 2010). En effet, le concept de la personnalité animale permet de classer les individus en tant que audacieux ou timides (shynessboldness axis), et se réfère à plusieurs traits comportementaux corrélés et des traits physiologiques sous-jacents exprimés chez les individus d'une manière stable dans le temps, quel que soit le contexte. Le concept similaire, le coping style, se réfère à la manière dont les individus font face à des situations particulières, souvent impliquant le stress (Koolhaas et al., 1999; Coppens et al., 2010).

Les «leaders» peuvent être associés aux individus téméraires ou proactifs, et les «followers » aux individus timides ou réactifs. Les «leaders" sont capables d'explorer un nouvel environnement en situation de danger potentiel et ce, sans avoir recours à une information sociale émise par les conspécifiques. En effet, les individus qui montent la passe en premier possèdent une appréciation du nouvel environnement moins riche que les individus qui le suivront. Les «followers " ont accès à cette information laissée par les «leaders" (mucus, signaux d'alarme, hormones de 



Fig. 8. Les niveaux de transcription des gènes des différents groupes de la variable peloton.

Fig. 8. Genes with significant differences in transcription levels among the groups of 'peloton' variable.

stress), et pourraient l'utiliser avant de prendre une décision sur le comportement à adopter (escalader ou pas). La perception et l'analyse des informations environnementales sont des composantes des processus cognitifs. Dans cette perspective, nous pouvons expliquer la sollicitation de gènes impliqués dans la cognition animale chez les "followers", mais aussi faire des liens entre le comportement des «followers" et le coping style réactif, puis le comportement des «leaders" et le coping style proactif des individus.

On a également remarqué que l'absence de «leaders» dans le groupe d'individus échantillonnés en aval du premier ouvrage pourrait avoir une signification écologique. En effet, le comportement proactif des «leaders" signifierait que les individus une fois arrivés au pied de l'obstacle tenteront de le franchir, même si cela nécessite d'exprimer un nouveau comportement (l'escalade, sortie en dehors de l'eau) et d'explorer une nouvelle zone. Ils pourraient effectuer l'escalade en absence de congénères sur la passe. Leur fenêtre de passage par l'obstacle est donc plus large que celle des individus réactifs («followers ") qui eux sont toujours en attente d'un individu proactif, initiateur du mouvement d'escalade, qui sera par la suite copié par les congénères.

D'une manière générale, il existe une certaine analogie entre les 
résultats ci-présents et la théorie des mouvements migratoires des civelles proposée par Feunteun et al., (2003) mais aussi la perception du mouvement migratoire des civelles comme processus densité-dépendant (Geffroy \& Bardonnet, 2012). En effet, les «leaders» pourraient faire partie des individus «pionneers» décrit par Feunteun et al., (2003), alors que les «followers » pourraient être associés aux «founders». On s'attend également à ce que la probabilité de trouver un «leader» augmente avec la taille du groupe présent au pied du barrage, alors la densité-dépendance de la migration n'exclut pas le mécanisme de succession des «followers » après les «leaders » décrit ici.

\section{Conclusion et perspectives}

Bien que la fragmentation du milieu soit considérée parmi les causes importantes du déclin des migrateurs, peu d'études portent sur les conséquences des obstacles aquatiques sur la qualité des individus et la distribution des patterns phénotypiques de l'espèce. Notre étude était la première à adopter une approche expérimentale individu-centrée, visant à détecter les traits phénotypiques différant entres anguillettes trouvées en amont et en aval des obstacles aquatiques. On a également adopté une démarche sans a priori grâce aux outils moléculaires récents, qui ont permis de comparer simultanément un nombre des gènes important au lieu de se focaliser uniquement sur les traits mentionnés dans la littérature scientifique. Cette démarche a permis de détecter les gènes qui n'ont pas été testés auparavant, et a permis d'attribuer au cerveau un rôle primordial dans le phénomène de franchissement de barrages. En effet, parmi les trois tissus testés, seul le tissu cervical possédait des séquences génétiques à transcription différente entre les sites. La fonction majeure des gènes détectés concerne la plasticité synaptique, qui est impliquée dans le processus cognitifs de l'animal. La régulation de cette fonction est de plus relativement stable dans le temps, puisque les différences entre les groupes d'échantillonnage étaient visibles même après deux mois de maintien de poissons sous conditions strictement homogènes, suggérant que la base de ces traits serait génétique ou épigénétique. Si des mécanismes épigénétiques sont en jeu, la régulation des gènes détectés pourrait être, entre autres, induite lors du passage par les obstacles. Dans ce cas, on pourrait parler d'un enrichissement du pool épigénétique de la population d'anguilles. L'épigénétique est une discipline récente et la notion de polymorphisme épigénétique demeure encore peu étudiée et ne fait que commencer à se faire une place à côté du concept de diversité génétique (Morange 2005 ; Neildez-Nguyen et al., 2008; Grativol et al., 2012; Markov et al., 2014 ; Avramidou et al., 2015). Dans le cas des anguilles, une étude expérimentale a déjà suggéré l'implication des mécanismes épigénétiques dans les normes de réaction observés (Côté et al., 2014). D'une manière générale, les modifications épigénétiques permettrait une évolution plus rapide que les variations génétiques (mutations, par exemple) (Bossdorf 
et al., 2008). Cependant, pour qu'il y ait des effets évolutifs à long terme de cet enrichissement du pool épigénétique, les marques épigénétiques doivent être héréditaires. Or, l'héritabilité des traits épigénétiques reste sujet à débat (Crews \& Gore, 2014), et la validation de cette hypothèse nécessiterait des analyses complémentaires. Dans le cas où les profils transcriptomiques auraient une base génétique, la présence des obstacles aquatiques serait un filtre sélectif, ce qui pourrait aboutir à l'appauvrissement du pool génétique à long terme. En effet, si la valeur sélective des génotypes retrouvés en amont des obstacles est différente, alors la composition des traits génétiques à la génération suivante pourrait être modifiée. Bien que l'aptitude phénotypique différentielle du sexe reste à démontrer chez l'anguille, cette perspective donne des pistes à explorer à l'avenir. On sait, par exemple, que la proportion de femelles retrouvées en amont est plus forte qu'en aval (Oliveira \& McCleave, 2000). Bien que le déterminisme du sexe serait influencé aussi bien par une composante génétique qu'environnementale (Krueger \& Oliveira, 1999; Geffroy, 2013; Côté et al., 2015; Geffroy \& Bardonnet, 2015), on pourrait supposer que les individus exprimant des profils transcriptomiques cérébraux particuliers (=équipés de certaines bases génétiques) peuvent passer les obstacles et ainsi présenter une plus forte probabilité de devenir femelle. La surexpression de l'aromatase, hormone responsable entre autres de la transformation du testostérone en œstradiol et donc de la féminisation du cerveau (Garcia-Segura, 2008; Diotel et al.,
2010; Le Page et al., 2010), a été observée chez les individus en amont (Podgorniak et al., 2015a), renforçant ainsi cette hypothèse.

Un autre point important concerne la survie plus faible des individus en amont par rapport à ceux en aval, et ceci indépendamment du sexe. Par exemple, lors de la migration de reproduction, les individus en amont doivent traverser les obstacles dans le sens inverse ce qui, dans le cas des installations hydroélectriques, implique une forte mortalité due au passage par les turbines (Boubee \& Williams, 2006; Gomes \& Larinier, 2008; Travade et al., 2010). Dans ce cas, les mesures prises pour améliorer la connectivité dans le sens aval-amont dans les axes aquatiques segmentés par des barrages (équipement des passes à civelles, augmentation de l'attractivité des dispositifs, voire translocation des civelles), pourraient être contre-productives, car la zone amont serait en quelque sorte un piège écologique pour l'anguille (Pelicice \& Agostinho, 2008; Agostinho et al., 2011; McLaughlin et al., 2012). D'une génération à l'autre, le polymorphisme génétique de l'anguille pourrait être appauvri par la faible survie des profils génétiques propres aux individus en «amont ». D'une manière générale, un piège écologique d'origine anthropique pourrait devenir par la suite un piège évolutif, si l'espèce n'a pas le temps de s'adapter à ces changements (Robertson et al., 2013). Dans le cas de l'anguille c'est particulièrement vrai, car même si le changement (i.e. construction et équipement des obstacles facilitant la connectivité dans un sens unique) se fait sur un temps 
générationnel relativement long, la panmixie pourrait empêcher la mise en place de toute adaptation locale de l'espèce.

Le tri comportemental réalisé sur le dispositif de la Passe Expérimentale a permis de séparer les individus en fonction de leur comportement d'escalade. Ainsi, chaque individu a été classé en tant que "leader», "follower», «finisher» ou «no climber». Cette classification a permis d'associer le niveau de transcription des gènes aux groupes comportementaux et non aux sites d'échantillonnage. En effet, aucune différence de transcription des gènes n'a été détectée en fonction de la provenance de l'individu, ces différences étant probablement masquées par les événements d'escalade effectuées dans les conditions expérimentales après l'échantillonnage. Les résultats les plus marquants concernent:

- les niveaux de transcription des gènes différents entre les "leaders » et «followers»;

- l'absence des «leaders" dans la partie la plus aval, au pied du premier obstacle.

Les «leaders» expriment un comportement d'exploration d'une nouvelle zone dans un contexte particulier, avec peu ou en l'absence totale de stimuli environnementaux provenant d'autres individus ayant déjà escaladé (par exemple, signaux d'alerte, hormones de stress), permettant d'estimer le niveau de risque lors de leur engagement sur la Passe Expérimentale. Ils expriment un comportement potentiellement à risque, en quelque sorte similaire au comportement des individus «téméraires» décrits dans les études de personnalité animale ou encore des individus "proactifs » définis selon la manière dont ils répondent aux situations de stress. Les «leaders " possédaient des niveaux de transcription des gènes liés à la cognition plus faibles que les individus "followers". Ce résultat prend beaucoup de sens lorsqu'il est replacé dans le contexte de stress coping style des animaux, où les individus proactifs (les «leaders") possèdent une performance cognitive moins forte que les individus réactifs (les «followers») (Johansen et al., 2012; Bousquet et al., 2015; Wong et al., 2015).

L'absence des «leaders》 au pied du premier obstacle peut signifier que les individus de ce profil comportemental peuvent avoir une fonction particulière dans la dynamique du groupe des civelles en cours de migration. En effet, la migration des jeunes stades d'anguille est vue comme un mouvement collectif, et tous les facteurs mentionnés jusqu'à présent dans la littérature qui influenceraient ce comportement, ne permettent pas toujours de prédire efficacement leur arrivée (observations personnelles). Si on regarde de plus près, ces facteurs concernent les paramètres abiotiques (les marées, cycle circadien, température) ou les variables intrinsèques des individus (réserves énergétiques, taux d'hormones thyroïdiennes circulantes, facteur de condition, stade ontogénétique). Or, la migration des civelles étant un mouvement de groupe, son comportement et sa dynamique pourraient être influencés par des paramètres intrinsèques non à l'individu mais aussi à la composition du groupe entier (Keiser \& Pruitt 2014; Modlmeier et al., 2014; 
Farine et al., 2015). En effet, de nombreuses études ont contribué à la création du concept de l'individu clé-de voûte (Modlmeier et al., 2014) en démontrant que la présence d'un faible nombre d'individus, voire d'un seul individu avec des traits ou comportements particuliers pourrait changer drastiquement le comportement du groupe entier (King, 2010). La littérature foisonne d'exemples dans ce sens (Collignon \& Detrain, 2010; Petit \& Bon, 2010; Pillot \& Deneubourg, 2010). Par exemple, chez certaines araignées sociales, l'ajout d'un individu extrêmement téméraire influence positivement le comportement d'audace du groupe entier (Pruitt \& Keiser, 2014). II existe également un feedback social positif, où la composition des individus timides, avec une tendance à suivre des individus capables d'une initiative particulière, accentue le comportement de leadership chez les individus proactifs (Harcourt et al., 2009). Le mouvement d'escalade observé chez les civelles en groupe pourrait être déclenché par les individus capables d'un comportement d'initiative, capacité d'exploration d'une nouvelle zone en dehors du milieu aquatique habituel et sans besoin de présence préalable de congénères. Dans ce contexte, nous pourrions suggérer qu'un apport d'individus téméraires, capables d'explorer le milieu en tant que «leaders" - et souvent retrouvés en amont de l'axe-dans les groupes d'individus en aval-encore naïfs aux obstacles, permettrait d'accélérer et faciliter le mouvement migratoire de toute la cohorte et ainsi mieux étaler l'occupation du milieu d'eau douce par l'anguille.

\section{RÉFÉRENCES}

Agostinho C.S., Pelicice F.M., Marques E.E., Soares A.B. \& de Almeida D.A.A., 2011. All that goes up must come down? Absence of downstream passage through a fish ladder in a large Amazonian river. Hydrobiologia 675: 1-12.

Avramidou E.V., Ganopoulos I.V., Doulis A. G., Tsaftaris A.S. \& Aravanopoulos F. A., 2015. Beyond population genetics: natural epigenetic variation in wild cherry (Prunus avium). Tree Genet. Genomes 11 (5), n' 95. DOI: $10.1007 /$ s11295-015-0921-7.

Bossdorf O., Richards C.L. \& Pigliucci M., 2008. Epigenetics for ecologists. Ecol. Lett. 11: 106-115.

Boubee J.A.T. \& Williams E.K., 2006. Downstream passage of silver eels at a small hydroelectric facility. Fish. Manag. Ecol. 13: 165-176.

Bousquet C.A.H., Petit O., Arrivé M., Robin J.P. \& Sueur C., 2015. Personality tests predict responses to a spatial-learning task in mallards, Anas platyrhynchos. Anim. Behav. 110: 145-154.

Collignon B. \& Detrain C., 2010. Distributed leadership and adaptive decision-making in the ant Tetramorium caespitum. Proc. Biol. Sci. 277: 1267-1273.

Coppens C.M., De Boer S.F. \& Koolhaas J. M., 2010. Coping styles and behavioural flexibility: Towards underlying mechanisms. Philos. Trans. R. Soc. B. Biol. Sci. 365: 4021-4028.

Côté C.L., Castonguay M., Kalujnaia M.S., Cramb G. \& Bernatchez L., 2014. In absence of local adaptation, plasticity and spatially varying selection rule: $\mathrm{A}$ view from genomic reaction norms in a panmictic species (Anguilla rostrata). BMC Genomics 15 (403). DOI: 10.1186/1471-2164-15-403.

Côté C.L., Pavey S.A., Stacey J.A., Pratt T.C., Castonguay M., Audet C. \& 
Bernatchez L., 2015. Growth, female size, and sex Ratio variability in American eel of different prigins in both controlled conditions and the wild: Implications for stocking programs. Trans. Am. Fish. Soc. 144: 246-257.

Cote D., Kehler D.G., Bourne C. \& Wiersma Y.F., 2009. A new measure of longitudinal connectivity for stream networks. Landsc. Ecol. 24: 101-113.

Crews D. \& Gore A.C., 2014. Chapter 26-Transgenerational epigenetics: Current controversies and debates. In: Transgenerational Epigenetics (T. Tollefsbol, Ed.), pp. 371-390. Oxford: Academic Press.

Croze O. \& Larinier M., 2007. Mitigation de l'impact des seuils et barrages sur la circulation des poissons migrateurs en rivière: solutions techniques et limites. (C. G. a. m. e. f. T. n. d. c. e. i. environnementale, Ed.), pp. 155-159. Paris: SHF-AIPCN-CETMEF.

Davey A. \& Jellyman D., 2005. Sex determination in freshwater eels and management options for manipulation of sex. Rev. Fish Biol. Fish. 15: 37-52.

Diotel N., Le Page Y., Mouriec K., Tong S. K., Pellegrini E., Valliant C., Anglade I., Brion F., Pakdel F., Chung B.C. \& Kah O., 2010. Aromatase in the brain of teleost fish: Expression, regulation and putative functions. Front. Neuroendocrinol. 31: 172-192.

Farine D.R., Montiglio P.O. \& Spiegel O., 2015. From individuals to groups and back: the evolutionary implications of group phenotypic composition. Trends Ecol. Evol. 30: 609-621.

Feunteun E., Laffaille P., Robinet T., Briand C., Baisez A., Olivier J.-M. \& Acou A., 2003. A review of upstream migration andmovements in inland waters by anguillid eels: toward a general theory. In: Eel Biology (K. Aida, K. Tsukamoto \&
K. Yamauchi, Eds.), pp. 181-190. Tokyo: Springer.

Garcia-Segura L.M., 2008. Aromatase in the brain: not just for reproduction anymore. J. Neuroendocrinol. 20: 705-712.

Garenc C., Silversides F.G. \& Guderley H., 1998. Burst swimming and its enzymatic correlates in the threespine stickleback (Gasterosteus aculeatus): full-sib heritabilities. Can. J. Zool. -Rev. Can. Zool. 76: 680-688.

Geffroy B., 2013. Déterminisme environnemental du sexe chez l'anguille européenne (Anguilla anguilla L.). Thèse de doctorat-spécialité physiologie et biologie des organismes-populationsinteractions, Université de Pau et des pays de l'Adour-École doctorale 211 sciences exactes et leurs applications, pp. 408.

Geffroy B. \& Bardonnet A., 2012. Differential effects of behaviour, propensity to migrate and recruitment season on glass eels and elvers' growing performance. Ecol. Freshw. Fish 21: 469-482. DOI: 10.1111/j.1600-0633.2012.00566.x.

Geffroy B. \& Bardonnet A., 2015. Sex differentiation and sex determination in eels: Consequences for management. Fish Fish. 17 (2), 375-398. DOI: 10.111/faf.12113.

Gomes P. \& Larinier M., 2008. Dommage subis par les anguilles lors de leur passage au travers des turbines Kaplan-Établissement de formules prédictives, Rep. No. RA 08.05. GHAAPPE.

Grativol C., Hemerly A.S. \& Ferreira P.C.G., 2012. Genetic and epigenetic regulation of stress responses in natural plant populations. Biochim. Biophys. ActaGene Regul. Mech. 1819: 176-185.

Harcourt J.L., Ang T.Z., Sweetman G., Johnstone R.A. \& Manica A., 2009. Social feedback and the emergence of leaders and followers. Curr. Biol. 19: 248-252. 
Hasler C.T., Pon L.B., Roscoe D.W., Mossop B., Patterson D.A., Hinch S. G. \& Cooke S.J., 2009. Expanding the "toolbox" for studying the biological responses of individual fish to hydropower infrastructure and operating strategies. Environ. Rev. 17: 179-197. DOI: 10.1139/A09-008.

Johansen I.B., Sørensen C., Sandvik G.K., Nilsson G.E., Höglund E., Bakken M. \& Øverli O., 2012. Neural plasticity is affected by stress and heritable variation in stress coping style. Comp. Biochem. Physiol. Part D: Genom. Proteom. 7: 161-171.

Keiser C.N. \& Pruitt J.N., 2014. Personality composition is more important than group size in determining collective foraging behaviour in the wild. Proc. Biol. Sci. 281 (1796), n UNSP 20141424. DOI: 10.1098/rspb.2014.142.

King A.J., 2010. Follow me! I'm a leader if you do; I'm a failed initiator if you don't? Behav. Proccesses. 84: 671-674.

Koolhaas J.M., Korte S.M., De Boer S.F., Van Der Vegt B.J., Van Reenen C.G., Hopster H., De Jong I.C., Ruis M.A.W. \& Blokhuis H.J., 1999. Coping styles in animals: Current status in behavior and stress- physiology. Neurosci. Biobehav. Rev. 23: 925-935.

Krueger W.H. \& Oliveira K., 1999. Evidence for environmental sex determination in the American eel, Anguilla rostrata. Environ. Biol. Fish. 55: 381-389.

Laporte M., Pavey S.A., Rougeux C., Pierron F., Lauzent M., Budzinski H., Labadie P., Geneste E., Couture P., Baudrimont M. \& Bernatchez L., 2016. RAD-sequencing reveals within-generation polygenic selection in response to anthropogenic organic and metal contamination in North Atlantic Eels. Mol. Ecol. 25: 219-237. DOI: 10.1111/mec.13466.

Larinier M., 2001. Environmental issues, dams and fish migrations. In: Dams, fish and fisheries: Opportunities, challen- ges and conflict resolution (G. Marmulla, Ed.), pp. 45-90. FAO Fisheries Technical Paper 419.

Larinier M. \& Dartiguelongue J., 1989. La circulation des poissons migrateurs: le transit à travers les turbines des installations hydroélectriques. Bull. Fr. Pêch. Piscic. 3: 12-313, 1-90.

Le Page Y., Diotel N., Vaillant C., Pellegrini E., Anglade I., Mérot Y. \& Kah O., 2010. Aromatase, brain sexualization and plasticity: The fish paradigm. Eur. J. Neurosci. 32: 2105-2115.

Markov G., Yiğit N., Çolak E., Kocheva M. \& Gospodinova M., 2014. Intraspecific epigenetic polymorphism of the East European vole (Microtus levis Miller, 1908) in South-eastern Europe and Turkey. Biol. (Pol.) 69: 101-106.

Martinez M., Guderley H., Dutil J.D., Winger P.D., He P. \& Walsh S.J., 2003. Condition, prolonged swimming performance and muscle metabolic capacities of cod Gadus morhua. J. Exp. Biol. 206: 503-511.

McDowall R.M., 1988. Diadromy in fishesMigration between freshwater and marine environments. London: Croom Helm.

McLaughlin R.L., Smyth E.R.B., CastroSantos T., Jones M.L., Koops M.A., Pratt T.C. \& Vélez-Espino L.A., 2012. Unintended consequences and tradeoffs of fish passage. Fish Fish. 14: 580604.

Modlmeier A.P., Keiser C.N., Watters J.V., Sin A. \& Pruitt J.N., 2014. The keystone individual concept: An ecological and evolutionary overview. Anim. Behav. 89: 53-62.

Morange M., 2005. How to localize epigenetics in the landscape of biological research? Med./Sci. 21: 367-369.

Neildez-Nguyen T.M.A., Parisot A., Vignal C., Rameau P., Stockholm D., Picot J., Allo V., Le Bec C., Laplace C. \& Paldi A., 
2008. Epigenetic gene expression noise and phenotypic diversification of clonal cell populations. Differentiation 76: 33-40.

Nicola G.G., Elvira B. \& Almodovar A., 1996. Dams and fish passage facilities in the large rivers of Spain: effects on migratory species. Archiv für Hydrobiol. 113: 375-379.

Oliveira K. \& McCleave J.D., 2000. Variation in population and life history traits of the American eel, Anguilla rostrata, in four rivers in Maine. Environ. Biol. Fish. 59: 141-151.

Pavey S.A., Gaudin J., Normandeau E., Dionne M., Castonguay M., Audet C. \& Bernatchez L., 2015. RAD sequencing highlights polygenic discrimination of habitat ecotypes in the panmictic American eel. Curr. Biol. 25: 1666-1671.

Pelicice F.M. \& Agostinho A.A., 2008. Fishpassage facilities as ecological traps in large neotropical rivers. Conserv. Biol. 22: $180-188$.

Pépino M., Rodríguez M.A. \& Magnan P., 2012. Fish dispersal in fragmented landscapes: A modeling framework for quantifying the permeability of structural barriers. Ecol. Appl. 22: 14351445.

Petit O. \& Bon R., 2010. Decision-making processes: The case of collective movements. Behav. Processes. 84: 635-647.

Pillot M.H. \& Deneubourg J.L., 2010. Collective movements, initiation and stops: Diversity of situations and law of parsimony. Behav. Processes. 84: 657-661.

Podgorniak T., 2016. Impact des obstacles aquatiques sur la migration des jeunes stades d'Anguilla anguilla. Thèse Écologie, Environnement. Université de Bordeaux.

Podgorniak T., Milan M., Pujolar J.M., de Oliveira E., Pierron F. \& Daverat F., 2015a. Differences in brain gene transcription profiles advocate for an important role of cognitive function in upstream migration and water obstacles crossing in European eel. BMC Genomics 16: 378.

Podgorniak T., Angelini A., Blanchet S., de Oliveira E., Pierron F. \& Daverat F., 2015b. Climbing experience in glass eels: A cognitive task or a matter of physical capacities? Physiol. Behav. 151: 448-455.

Podgorniak T., Blanchet S., De Oliveira E., Daverat F. \& Pierron F, 2016. To boldly climb: behavioural and cognitive differences in migrating European glass eels. R. Soc. Open Sci. 3: 150655. DOI: $10.1098 /$ rsos. 150665.

Pruitt J.N. \& Keiser C.N., 2014. The personality types of key catalytic individuals shape colonies' collective behaviour and success. Anim. Behav. 93: 87-95.

Robertson B.A., Rehage J.S. \& Sih A., 2013. Ecological novelty and the emergence of evolutionary traps. Trends Ecol. Evol. 28: 552-560.

Travade F., 2005. Migratory fish passage at hydroelectric facilities: EDF experience. Houille Blanche: 60-68.

Travade F., Larinier M., Subra S., Gomes P. \& De-Oliveira E., 2010. Behaviour and passage of European silver eels (Anguilla anguilla) at a small hydropower plant during their downstream migration. Knowl. Manag. Aquat. Ecosyst. 398, $\mathrm{n}^{\circ} 01$. DOI: 10.1051/kmae/ 2010022.

Ward J.V. \& Stanford J.A., 1979. The ecology of regulated streams. New York: Plenum.

Wong R.Y., Lamm M.S. \& Godwin J., 2015. Characterizing the neurotranscriptomic states in alternative stress coping styles. BMC Genomics 16, $\mathrm{n}^{\circ} 425$. DOI: 10.1186/s12864-015-1626-x. 